\title{
Curriculum, Creativity, Circus, and Chapters: A Review of the ISSOTL 2014 Conference
}

The annual International Society for the Scholarship of Teaching and Learning (ISSOTL) 2014 conference was held in picturesque Quebec City. Hosted by Laval University, the conference was a Mecca for the dissemination of information, debate, development, and engagement. This year saw a number of innovative practices, including the addition of an ISSOTL mobile application which kept delegates informed of sessions and areas of interest. One of the most inspiring aspects of the conference was the incredible manner in which the keynote addresses were scribed in both visual and textual formats. This enabled delegates to appreciate the key messages within the plenary sessions. The scribing of conceptual and contextual ideas on a whiteboard not only flooded the Twitter lines, but more importantly painted a picture of what the future for SoTL publication may become.

The conference attracted a wealth of expertise across multiple levels of learning and learners. The theme for the conference captured the uniqueness of creative expression in teaching and learning. This was carefully developed through the plenary sessions which ranged from transformational learning and critical pedagogies to the expression of "delicious uncertainty," to learning as a practised identity and understanding how to navigate among and between learning chapters.

Apart from the oral, poster, symposia, and workshop presentations, the annual conference further provided important meeting spaces for its numerous special interest groups. These groups gathered to communicate the ethos, vision, and work of the Society by focussing specifically on key learning issues within specialist areas. Some of the groups developed proposals for a new series of textbooks to examine the scholarship of teaching and learning through different and innovative SoTL lenses. Lunch time and early breakfast meetings saw members of these special interest group learn, lead, and often lend support to their colleagues.

There were a number of regional specific meetings to mobilise interest amongst members from different geographical locations. The importance of ISSOTL is best captured in the way members from regional groups disseminate information and learning to their regions and institutions, and engage colleagues with the value of SoTL, even if the term is alien and/or problematic to many. The conference further witnessed the meeting of journal editors to debate the future of SoTL publications and the impact of open access publication on academic scholarship.

International liaison and collaboration are critical to the success of the Society, its present and future endeavours, yet the future of SoTL relies on the process by which 
student voices are heard and how these relationships are cultivated, acknowledged and included in the discourse of the conference. It was pleasing to see panel discussions where students were active contributors to the design of modules and the curriculum in general. Through student narratives, audiences were able to listen to, and comprehend in part, the core concerns in student learning and engagement and question strategies for both improving and transforming student learning experiences.

ISSOTL 2014 will be remembered as the people's conference, a common space where scholars, academics, students, artists, practitioners, management, and educational leaders and advisors came together to inject humanity back into the way we speak about SoTL and document the work we do to improve and transform practices. This was the conference where we learned to settle into the unsettled, asked new and different questions, and embraced culture, creativity and language. Attendees did not only do SoTL, but more importantly, and in keeping with the conference theme, learned to speak SoTL. The conference provided the space for delegates to connect and reflect. This space was important for learning, collaboration, dissemination, and integration of pathways and research strands. New members were welcomed, students were engaged and encouraged to actively contribute, and more experienced colleagues were able to provide useful backdrops to the challenges, trials and tribulations of SoTL.

As the curtain closed on ISSOTL 2014, the learning experience and situational scribing remained etched in the memories and work of those who were able to attend. Through the conference, we learned to learn by acknowledging and embracing the challenges and opportunities for future SoTL inquiry.

As thoughts turned back to the classroom, and as delegates confronted their duties and responsibilities as educators, scholars, practitioners and leaders, we now look ahead with excitement and anticipation to the 2015 conference in Melbourne Australia, and aim to advance and develop the conversations and connections we made in 2014.

Well done to all who worked tirelessly to plan and produce an excellent conference. The richness of the programme and its supporting content is testimony to the strength of the Society and the way in which ideas and innovations are moved forward.

La conférence a été la célébration du succès et ont capturé la créativité et la passion du SoTL communauté.

Perhaps the conference can best be summarised in the words of Henry Ford: "Coming together is a beginning; keeping together is progress; working together is success."

Earle Abrahamson co-chairs the ISSOTL multinational teaching fellows group, is a senior lecturer in Sports Therapy at the University of East London, United Kingdom. Earle's research interests revolve around academic identity and troublesome knowledge, the scholarship of civic engagement, and graduate employability. 